\title{
DISCURSO DA PRESIDENTE EM EXERCíCIO
}

\author{
M. ${ }^{a}$ da Graça Simões Côrte Imperiaì
}

\begin{tabular}{|l|l|}
\hline$R B E n / 03$ \\
\hline
\end{tabular}

IMPERIAL, M.G.S.C. - Discurso da Presidente em Exercício - Rev. Bras. Enf., Rio de Janeiro, 28: 22-24, 1975.

Sejam as minhas primeiras palavras de agradecimento pela presença das dignas autoridades, presença que acolhemos como uma deferência à nossa Associação e o desejo de prestigiar esta solenidade.

Um sopro de renovação anima a vida dos povos nesta fase da história da humanidade. Renovação e, por conseguinte, transformação.

Não podendo ficar à margem desse expressivo movimento, que, modificando as estruturas dos velhos países, estimula os novos a encontrar novas fórmulas para se desenvolverem social e economicamente, a Enfermagem, através de sua Associação de classe reune seus associados com o objetivo de participar desta ascensão. Acompanha assim o desenvolvimento do País em todos os seus planos e programas de reformulação modernizante, ao nível do progresso social e tecnológico do mundo de hoje.

Encontros como este estimulam a troca de idéias e de experiências dos que trabalham na área da saúde, da educação, da administração e da previdência social; este tem sido o papel de relevância da Associação Brasileira de Enfermagem.

Tem grande significação para os Enfermeiros este Congresso, que hoje ins- talamos, porque segundo Charles Vanhech, vir à Bahia "é conhecer uma cidade portuguesa na sua arquitetura, na sua composição, na sua maneira de subir pelas colinas para melhor observar o oceano. Portuguesa é a língua que chia como a roda de uma carroça, portugueses são os cristos sanguinolentos de olhos vidrados, os santos bonachões, as Virgens de queixo duplo que estão no Museu de Arte Sacra e todos os conventcs desta cidade tão piedosa! Português também é o comércio de açúcar e do cacáu., cujo aroma impregna todo o bairro do Bonfim. Portuguesa a "saudade""' - a nostalgia, a falta com que os baianos definem seus amores e suas descobertas. Portuguesas mil outras coisas, exceto o essencial: "a vida e a festa que pertencem aos negros onde puseram uma máscara branca e a máscara é linda".

$\mathrm{Na}$ sua augusta velhice, Salvador o maior conjunto colonial da América do Sul, continua atraindo os turistas, seduzindo os visitantes e prendendo, no seu encantamento de sereia, o coração dos brasileiros.

Por tudo isso, vir à Bahia é um prazer: renovar a emoção de rever esta notávei cldade cheia de muitos encantos e sortilégics, obra prima da natureza e do homem; rever a boa gente desta 
IMPERIAL, M.G.S.C. - Discurso da Presidente em Exercício - Rev. Bras. Enf., Rio de Janeiro, 28: 22-24, 1975.

província onde o Brasil nasceu e, abraçar mais uma vez os colegas, os amigos que vivem aqui.

Não obstante, todos estes motivos para o elevo da alma, encaramos a Bahia presente, com a força de suas convicções da nacionalidade brasileira, com a pujança de seu desenvolvimento e com a força viva de sua gente, cujo pensamento e ação estão voltados para a grandeza do Brasil. Encaramos este pedaço de terra como uma das mais elevadas expressões da vida cultural do País.

Vir à Bahia, é sentir a terra que deu Ana Neri ao Brasil. Mulher admirável, fervorosa, misto de santa e de heroína que sem perder a substância do seu humanismo encarou com objetividade 0 duro realismo e os horrores da Guerra. Sua mensagem vive no coração dos baianos e de todos os enfermeiros que mantêm na lembrança sua figura cheia de amor ao próximo.

Falando nessa mulher admirável, não podemos omitir as comemorações do "Ano Internacional da Mulher", consagradas por declaração expressa das $\mathrm{Na}$ ções Unidas. Por que o Ano Internacional da Mulher, senão para reconhecer a igualdade de direitos e deveres para ambos os sexos; a capacidade da mulher em operar em qualquer ramo da ciência ou de atividade, não mais como a exceção honrosa de uma Florence Nightingale, de Madame Curie, ou de Joana D'Arc, mas com o direito às oportunidades abertas a todos, de acordo com as próprias potencialidades, aptidões e opções?

É bem verdade que a importância e significado da missão da mulher no lar nunca poderá ser esquecida ou subestimada; sua ação educativa de apoio e orientação é um dos esteios nos quais repousa a tranqüilidade e segurança de uma Nação. Seu poder aglutinador, define e caracteriza a base sociológica de um país organizado - a FAMíLIA.
Não se limite nisto a ação da mulher; educar é multiplicar o saber. A mulher ao transceder as ações do círculo familiar vencendo pouco a pouco mil obstáculos, está conquistando a elevada esfera cultural e a qualidade do desempenho das funções profissionais. Há bem pouco tempo, vimos na India e em Israel as elevadas posições de $10^{\circ} \mathrm{Mi}-$ nistro entregues a mulheres que as assumiram em situações bem difíceis. No Brasil há exemplos de Estados, como o Estado do Acre e atualmente o novo Estado do Rio de Janeiro em que a pasta da Secretaria de Educação é ocupada por ilustre representante do sexo feminino.

Mais orgulhosamente ainda citamos que, aqui na Bahia, por decisão honrosa de Sua Excelência o Senhor Governador Dr. Roberto Santos, a Secretaria do Bem-Estar Social foi entregue a uma mulher, Enfermeira que sempre se distinguiu na sua vida profissional, na sua vida Universitária como Professora e Vice-Reitora. Pedimos vênia para cumprimentar Sua Excelência pelo alto julgamento seletivo de entregar à Dra. Maria Ivete Ribeiro de Oliveira uma das Secretarias do seu Governo.

Como seria longa e bela a história das inúmeras dedicações de Enfermeiras que souberam honrar a profissão e muito contribuíram para o progresso da enfermagem; gratas somos a Laís Neto dos Reys, Edith de Magalhães Fraenkel, Marina de Andrade Resende, Ariadne Lopes de Menezes, Clélia de Pontes, Olga Salinas Lacorte e Glete de Alcântara. Queremos neste momento reverenciar suas memórias pelo muito que fizeram; o que nos legaram será para os futuros profissionais, acervo de grande valor e profundidade.

Prezados colegas:

Há 11 anos, realizou-se nesta cidade o XVI Congresso Brasileiro de Enfermagem sob a presidencia da Enfermeira Clarice Ferrarini. Com ela aqui estive- 
IMPERIAL, M.G.S.C. - Discurso da Presidente em Exercício - Rev. Bras. Enf., Rio de Janeiro, 28: 22-24, 1975.

ram reunidos profissionais vindos de todos os pontos do país e representantes de outros países com seus problemas, suas idéias e sugestões; todos inspirados no mesmo setimento de progredir. Os estudos aqui realizados, difundiram-se pelo país como se tem difundido os dos outros Congressos que lhe seguiram.

A enfermagem brasileira está dia a dia se tornando mais firme e segura de sua posição na equipe multiprofissional. As Instituições de Saúde, as áreas de ensino, de planejamento e administração identificaram há muito necessidade e importância de enfermagem exigindo sua colaboração indispensável em todas as ações de Saúde a nível local, regional e nacional.

A existência de Cursos de Pós Graduação a nível de Mestrado em algumas unidades Universitárias, está constituindo fator de relevância para o aperfeiçoamento do pessoal docente e do profissional em exercício. $\mathrm{Na}$ área do ensino médio, os Cursos de Técnico de Enfermagem serão para o futuro, fonte de reforço nos recursos humanos para a assistência direta aos pacientes hospitalizados e em serviços ambulatoriais. Com relação ao Ensino Supletivo em nivel de Auxiliar de Enfermagem multiplicam-se os Cursos intensivos que, se por um lado podem ameaçar a qualidade, na atenção de enfermagem, visto de forma positiva e com organização adequada irão reduzir o tempo necessário para serem substituídos os $70 \%$ de pessoal não habilitados ainda em atividade nos serviços hospitalares e para hospitalares do país. A profissionalização em enfermagem após o ensino de $10^{\circ}$ grau trará benefícios não só para o jovem à procura de uma ocupação, mas para a comunidade. O preparo de mão-de-obra está sendo intensificado na área da saúde. Os enfermeiros compreendendo a importância desses programas, têm colaborađo com o Mi- nistério do Trabalho auxiliando o planejamento e ministração de Cursos.

A Associação Brasileira de Enfermagem, por sua vez, consciente de suas responsabilidades tem se mantido sempre vigilante. Orientando ou assessorando autoridades nos interesses dos profissionais, incluindo os Técnicos de Enfermagem e Auxiliares de Enfermagem, nos documentos legais que direta ou indiretamente possam ter repercussão no ensino ou no exercício da enfermagem.

O Conselho Federal de Enfermagem, criado pela Lei n. ${ }^{\circ} 5.905$, de 12/7/73 e por nós instalado, em Brasília no dia 23 de abril de 1975 assumirá daqui por diante, as ações normativas, de fiscalização e de controle do exercício profissional de enfermagem em todo o país.

Está de parabéns a Comissão de Temas deste Congresso que tão bem soube escolner os assuntos a serem debatidos em Assembléias e em Grupos de Trabalho.

Ilustre Assembléia:

Agradecemos a generosidade do tempo dispensado que reverterá na melhor integração dos nossos objetivos.

Agradecemos a Sua Excelência Prof. Dr. Roberto Santos, D. D. Governador do Estado da Bahia, a honra concedida com a presença a esta solenidade e o apoio dado à realização deste congresso.

As autoridades, Universidades Estaduais, Municipais, Militares, Civis e Religiosas, agradecemos a presença e solidariedade recebida.

A Associação Brasileira de Enfermagem, Seção da Bahia, que nos hospeda pela segunda vez, gratas pela permanente dedicação à causa da Enfermagem.

Colegas congressistas, felicitamos a todos com entusiasmo, pelo esforço de participarem deste Encontro tão importante para a nossa vida profissional.

SEJAM BENVINDAS. 